\title{
Effect of the prosthesis-patient mismatch on long-term clinical outcomes after isolated aortic valve replacement for aortic stenosis: A prospective observational study
}

\author{
Soonchang Hong, MD, ${ }^{\mathrm{a}}$ Gijong Yi, MD, ${ }^{\mathrm{a}}$ Young-Nam Youn, MD, ${ }^{\mathrm{b}}$ Sak Lee, MD, ${ }^{\mathrm{b}}$ \\ Kyung-Jong Yoo, $\mathrm{MD},{ }^{\mathrm{b}}$ and Byung-Chul Chang, $\mathrm{MD}^{\mathrm{b}}$
}

\begin{abstract}
Background: The effect of prosthesis-patient mismatch (PPM) on clinical outcomes after aortic valve replacement remains controversial. We evaluated effect of PPM on long-term clinical outcomes after isolated aortic valve replacement in patients with predominant aortic stenosis.
\end{abstract}

\begin{abstract}
Methods: We analyzed data from patients with predominant aortic stenosis who underwent isolated aortic valve replacement between January 1995 and July 2010. The indexed effective orifice area, obtained by dividing the in vivo effective orifice area by the patient's body surface area, was used to define PPM as clinically nonsignificant (group I, 224 patients), mild (group II, 52 patients), moderate (group III, 39 patients), and severe (group IV, 36 patients).
\end{abstract}

Results: Early survival was not significantly different among the groups, but overall survival was decreased gradually in group IV. Overall survival at 12 years was lower in group IV than in group I $(92.8 \% \pm 2.7 \%$ vs $67.0 \pm 10.1$, respectively; $P=.001$ ). Cardiac-related-death-free survival at 12 years was lower in patients with severe PPM. Left ventricular mass index decreased during the follow-up period in all groups. But left ventricular mass index was less decreased in group IV compared with groups I, II, and III. Age, severe PPM, and ejection fraction $<40 \%$, and New York Heart Association Functional Class IV were independent risk factors of overall survival on multivariate analysis. Severe PPM was an independent risk factor for cardiac-related death.

Conclusions: Severe PPM showed an adverse effect on long-term survival, and was an independent risk factor for cardiac-related death. In addition, patients with severe PPM showed less decreasing left ventricular mass index during follow-up. (J Thorac Cardiovasc Surg 2013;146:1098-104)

Prosthesis-patient mismatch (PPM) occasionally occurs after aortic valve replacement (AVR). PPM is present when the effective orifice area (EOA) of an implanted prosthetic valve is too small relative to body size, which consequently generates higher pressure gradients through a normally functioning prosthetic valve. This hemodynamic change increases left ventricle work, reduces left ventricular mass regression, and produces clinical symptoms of aortic stenosis (AS). Several studies reported that PPM is an independent risk factor for midterm mortality, or long-term survival after AVR. ${ }^{1,2}$ If the PPM combined with low left ventricle function, short-term mortality was increased. ${ }^{3}$ But others demonstrated that severe PPM was predicted in $5 \%$ of patients undergoing AVR, and this did not

From the Department of Thoracic and Cardiovascular Surgery, ${ }^{\mathrm{a}}$ Gangnam Severance Hospital, and Division of Cardiovascular Surgery, ${ }^{\mathrm{b}}$ Yonsei Cardiovascular Hospital, Yonsei University College of Medicine, Seoul, Korea.

Disclosures: Authors have nothing to disclose with regard to commercial support.

Received for publication Sept 8, 2011; revisions received June 26, 2012; accepted for publication July 31, 2012; available ahead of print Sept 10, 2012.

Address for reprints: Byung-Chul Chang, MD, Division of Cardiovascular Surgery, Yonsei Cardiovascular Hospital, Yonsei University College of Medicine, Yonsei University Health System, 134 Shinchondong, Seodaemun-ku, Seoul, Korea, 120-752 (E-mail: bcchang@yuhs.ac).

$0022-5223 / \$ 36.00$

Copyright (c) 2013 by The American Association for Thoracic Surgery

http://dx.doi.org/10.1016/j.jtcvs.2012.07.101 affect mortality or midterm or long-term survival. ${ }^{4,5}$ Discrepancies may be related to differences in criteria used to define PPM and to quantify its severity, or differences in patient baseline characteristics. Our study was designed to evaluate the effect of PPM on regression of left ventricular mass index (LVMI) and long-term survival after AVR. To minimize bias, particularly on long-term survival, we included only patients who underwent isolated AVR for predominant AS in each group of our study since 1995 when we began to use various types of prostheses. This study was approved by the Institutional Review Board of Severance Hospital, Yonsei University Health System.

\section{METHODS}

\section{Patient Selection}

We analyzed data from 351 patients with predominant AS who underwent isolated AVR between January 1995 and June 2010. Patients with more than mild aortic regurgitation on preoperative transthoracic echocardiography were excluded, as were patients with significant coronary artery disease who had undergone percutaneous coronary intervention or concomitant coronary artery bypass grafting surgery. Patients who underwent other valvular surgery or ascending aorta graft replacement for poststenotic dilatation also were excluded.

\section{Prostheses}

We used various prostheses beginning in 1995. The type and size of prosthesis was recorded for each patient. The prostheses used were 


$$
\begin{aligned}
& \text { Abbreviations and Acronyms } \\
& \begin{aligned}
\text { AS } & =\text { aortic stenosis } \\
\text { AVR } & =\text { aortic valve replacement } \\
\text { EOA } & =\text { effective orifice area } \\
\text { LVMI } & =\text { left ventricular mass index } \\
\text { LVOT } & =\text { left ventricular outflow tract } \\
\text { PPM } & =\text { prosthesis-patient mismatch }
\end{aligned}
\end{aligned}
$$

Carpentier-Edwards S.A.V. (Edwards Lifescience, Irvine, Calif) in 89 patients (26\%), St Jude Medical standard (St Jude Medical, Inc, St Paul, Minn) in 80 patients (24\%), ATS (ATS Medical, Inc, Minneapolis, Minn) in 39 patients (11\%), Carbomedics (Sulzer CarboMedics, Inc, Austin, Tex) in 35 patients (10\%), St Jude Medical Epic (St Jude Medical, Inc) in 22 patients $(6.2 \%)$, Edwards MIRA (Edwards Lifescience) in 17 patients (4.8\%), MCRI On-X (Medical Carbon Research Institute, Austin, Tex) in 18 patients $(5 \%)$, Sorin Bicarbon (Sorin Biomedica Cardio Spa, Saluggia, Italy) in 14 patients (4\%), and Medtronic Hancock II (Medtronic, Inc, Minneapolis, Minn) in 9 patients ( $3 \%)$.

\section{Doppler Echocardiographic Measurements}

All patients underwent preoperative and postoperative 2-dimensional and Doppler echocardiographic evaluation, and underwent serial followup echocardiographic examination every 2 or 3 years, and as clinically indicated after operation. The in vivo EOA for prosthesis type and size was reported in previous studies of patients with normally functioning prostheses. $^{3,6-15}$ In our study, echocardiography was performed within 2 months after operation in all patients, the in vivo EOA was derived from the continuity equation: $\left(0.785 \times \mathrm{LVOT}^{2} \times \mathrm{TVI}_{1}\right) / \mathrm{TVI}_{2}$, where LVOT is the diameter of the left ventricular outflow tract, and $\mathrm{TVI}_{1}$ and $\mathrm{TVI}_{2}$ are the time-velocity integrals at the LVOT and across the aortic valve, respectively. The left ventricular mass was derived from the formula described by the American Society of Echocardiography:

$$
0.8 \times\left\{1.04\left[(\mathrm{LVID}+\mathrm{PWT}+\mathrm{IVST})^{3}-\mathrm{LVID}^{3}\right]\right\}+0.6
$$

in which LVID is left ventricular internal diameter, PWT is posterior wall thickness, and IVST is interventricular septal thickness (all diastolic measurements). Echocardiography was performed within 2 months after operation.

\section{PPM Definition}

Indexed EOA was obtained by dividing in vivo EOA by a patient's body surface area at the time of operation and was available for all patients. The reference group comprised patients with an indexed EOA $>0.85 \mathrm{~cm}^{2} / \mathrm{m}^{2}$ (group I, 224 patients). PPM was defined as mild if the indexed EOA was $\leq 0.85 \mathrm{~cm}^{2} / \mathrm{m}^{2}$ but $>0.75 \mathrm{~cm}^{2} / \mathrm{m}^{2}$ (group II, 52 patients), moderate if indexed EOA was $\leq 0.75 \mathrm{~cm}^{2} / \mathrm{m}^{2}$ but $>0.65 \mathrm{~cm}^{2} / \mathrm{m}^{2}$ (group III, 39 patients), and severe if indexed EOA $<0.65 \mathrm{~cm}^{2} / \mathrm{m}^{2}$ (group IV, 36 patients).

\section{Data Collection}

Prospective intraoperative and postoperative data were collected from the registry database. Data related to survival were obtained by telephone interview with patients, their family, or from the Korean Statistical Information Service. The primary end point was all-cause mortality, including in-hospital mortality. Follow-up information was available on all 351 patients. The closing interval was from March 2011 to April 2011.

\section{Statistical Analysis}

In comparing the preoperative characteristics, continuous variables were expressed as mean \pm standard deviation, and categorical data were tabulated as frequencies and percentages. For continuous variables, data were compared using the $\chi^{2}$ test or Student $t$ test. All reported probability values were 2 -sided. We analyzed the difference of LVMI according to postoperative time after AVR using regression analysis, and compared coefficient and confidence interval (CI). Overall survival and cardiac-relateddeath free survival were calculated using the Kaplan-Meier method and reported with $95 \%$ confidence limits. The effect of PPM on clinical outcomes after AVR was determined using Cox regression, and results are expressed as hazard ratio (HR) with $95 \%$ CI. Among risk factors, those with a $P$ value $\leq .1$ were selected for multivariate analyses. The multivariate model was constructed by the enter method. All data were analyzed using the SPSS software package for Windows (version 18.0, 2009; IBM, Armonk, NY).

\section{RESULTS}

PPM was nonexistent in 224 patients (group I, 63.8\%). Mild PPM was identified in 52 patients (group II, 14.8\%), moderate PPM was identified in 39 patients (group III, $11.1 \%$ ), and severe PPM was identified in 36 patients (group IV, 10.3\%). Preoperative and operative patient characteristics are listed in Table 1. Compared with patients without PPM (group I), those with severe PPM had a higher prevalence of women $(P=.05)$. Most implanted prostheses were $<19 \mathrm{~mm}$ in group IV, and mechanical prosthesis was used more frequently in group I.

\section{In-Hospital Outcomes}

In-hospital outcomes are listed in Table 2. Three deaths occurred in group I ( $2.3 \%), 2$ in group II $(3.8 \%), 1$ in group III, and none in group IV with no significant differences among the groups $(P=.47)$. There were also no differences in the prevalence of postoperative renal failure, cerebrovascular accident, or bleeding among the groups.

\section{Affect on LVMI}

There was significant difference in LVMI regression between groups (Table 2). The change of LVMI according to postoperative time was analyzed. LVMI was decreased after AVR during follow-up period in all groups irrespective of presence of PPM (Figure 1). To compare the difference of LVMI during the follow-up period, we analyzed coefficient and $\mathrm{CI}$ in each group (Figure 2). The bars show the $95 \% \mathrm{CI}$, and the values of group IV showed less negative quantities than those of others. This shows that LVMI in group IV was less decreased comparing with group I, II, and III during the follow-up period after AVR $(P<.05)$.

\section{PPM and Survival}

During the follow-up period, the number of deaths was 10 in group I, 5 in group II, 5 in group III, and 8 in group IV. Overall survival at 4 years was $97.6 \% \pm 1.6 \%$ for patients in group I, $94.7 \% \pm 3.7 \%$ in group II, $92.2 \% \pm$ $3.7 \%$ in group III, and $90.8 \% \pm 5.1 \%$ in group IV. There were no significant differences in 4-year overall survival among the groups. However, as time passed overall survival in group IV decreased gradually, and patients in groups IV 
TABLE 1. Baseline preoperative and operative data

\begin{tabular}{|c|c|c|c|c|c|}
\hline & Group I $(n=224)$ & Group II $(n=52)$ & Group III $(\mathbf{n}=39)$ & Group IV $(n=36)$ & $\boldsymbol{P}$ \\
\hline Age (y) & $59.6 \pm 11.7$ & $58.9 \pm 18.0$ & $59.0 \pm 13.0$ & $61.8 \pm 14.4$ & .76 \\
\hline Woman & $87(38.8)$ & $23(44.2)$ & $13(33.3)$ & $22(61.1)$ & .05 \\
\hline NYHA Functional Class $>3$ & $14(6.3)$ & $3(5.8)$ & $1(2.6)$ & $2(5.6)$ & .70 \\
\hline Diabetes mellitus & $26(11.9)$ & $9(17.6)$ & $9(25.9)$ & $8(22.9)$ & .09 \\
\hline Obesity* & $76(33.9)$ & $20(38.5)$ & $19(48.7)$ & $15(41.7)$ & .31 \\
\hline Hypertension & $59(26.3)$ & $11(21.2)$ & $12(30.8)$ & $13(36.1)$ & .43 \\
\hline End-stage renal disease & $6(2.7)$ & $2(3.9)$ & $0(0.0)$ & $9(5.7)$ & .52 \\
\hline Cerebral vascular disease & $8(3.7)$ & $2(3.9)$ & $2(5.6)$ & $2(5.7)$ & .91 \\
\hline Peripheral artery obstructive disease & $4(1.8)$ & $1(2.0)$ & $0(0.0)$ & $0(0.0)$ & .72 \\
\hline Endocarditis & $2(0.9)$ & $2(3.8)$ & $1(2.6)$ & $0(0.0)$ & .32 \\
\hline Ejection fraction $<40$ (preoperative) & $31(13.8)$ & $10(19.2)$ & $2(5.1)$ & $3(8.3)$ & .19 \\
\hline Ejection fraction (preoperative) & $58.5 \pm 15.1$ & $58.4 \pm 16.8$ & $58.8 \pm 13.0$ & $61.4 \pm 14.8$ & .75 \\
\hline LVMI (preoperative $\mathrm{g} / \mathrm{m}^{2}$ ) & $175 \pm 69.9$ & $190 \pm 52.5$ & $175 \pm 43.7$ & $171 \pm 35.1$ & .40 \\
\hline Peak pressure gradient $(\mathrm{mm} \mathrm{Hg})$ & $81.1 \pm 18.8$ & $77.8 \pm 14.7$ & $78.2 \pm 17.4$ & $83.6 \pm 20.8$ & .36 \\
\hline Mean pressure gradient (mm Hg) & $50.2 \pm 12.2$ & $46.6 \pm 11.2$ & $47.6 \pm 10.6$ & $51.3 \pm 13.9$ & .18 \\
\hline Mechanical prosthesis & $158(70.5)$ & $31(59.6)$ & $22(56.4)$ & $17(47.2)$ & .01 \\
\hline \multicolumn{6}{|l|}{ Prosthesis } \\
\hline$\leq 21 \mathrm{~mm}$ & $105(47)$ & $32(62)$ & $33(85)$ & $35(97)$ & $<.05$ \\
\hline$\leq 19 \mathrm{~mm}$ & $18(8)$ & $9(17)$ & $30(77)$ & $33(92)$ & $<.05$ \\
\hline ACC time (min) & $103 \pm 25.1$ & $91.8 \pm 27.9$ & $92.8 \pm 25.1$ & $91.3 \pm 24.1$ & .29 \\
\hline CPB time (min) & $130 \pm 39.7$ & $142 \pm 40.1$ & $124 \pm 35.6$ & $129 \pm 34.6$ & .73 \\
\hline
\end{tabular}

Values are presented as mean \pm standard deviation or number (\%). NYHA, New York Heart Association; $L V M I$, left ventricular mass index; $A C C$, aortic cross clamp; $C P B$, cardiopulmonary bypass. *Defined as body mass index $>25$.

had significantly lower overall survival rates after 14 years. Overall survival at 12 years was $92.8 \pm 2.7 \%$ for patients in in group I, $87.8 \% \pm 5.6 \%$ in group II, $84.7 \% \pm 6.4 \%$ in group III, and $67.0 \% \pm 10.1 \%$ in group IV (Figure 3). In patients with preserved left ventricular ejection fraction $(>40 \%$ ), overall survival at 12 years was $96.0 \% \pm 1.7 \%$ for patients in group I, and $68.3 \% \pm 10.5 \%$ in group IV $(P=.001)$.

Multivariate analysis showed that age (HR, 1.24; $95 \%$ CI, 1.10-1.39; $P=.01)$, preoperative left ventricular ejection fraction (HR, 1.10; 95\% CI, 1.02-1.18; $P=.01$ ), New York Heart Association Functional Class IV (HR, $18.7 ; 95 \% \mathrm{CI}, 1.37-25.5 ; P=.02)$, and severe PPM (HR, $6.42 ; 95 \% \mathrm{CI}, 1.14-35.8 ; P=.03)$ were adverse predictors of overall survival (Table 3 ).

During the follow-up period, the number of cardiacrelated deaths was 3 in group I, 1 in group II, 1 in group III, and 4 in group IV. Cardiac-related-death-free survival at 4 years was $99.6 \% \pm 0.6 \%$ for patients in group I, and $98.1 \% \pm 1.9 \%, 96.4 \% \pm 3.5 \%$, and $97.2 \% \pm 2.7 \%$ in groups II, III, and IV, respectively, with no statistically significant differences between groups. However, cardiacrelated-death-free survival at 12 years was significantly lower in group IV $(81.0 \% \pm 9.2 \%)$ than in groups I, II, and III $(96.3 \% \pm 2.3 \%, 98.1 \% \pm 1.9 \%$, and $96.4 \% \pm$ $3.5 \%$, respectively) $(P=.01)$ (Figure 4$)$.

Multivariate analysis showed that severe PPM was independently associated with cardiac-related mortality (HR, 10.4; 95\% CI, 1.14-92.1; $P=.03$ ), but mild and moderate PPM were not independent predictors (Table 4).

\section{COMMENT}

A small prosthesis may need to be inserted because of pathologic processes such as annular calcification and fibrosis that can reduce the size of the aortic annulus resulting in a prosthetic EOA less than that of the native valve. The concept that moderate AS is present in a native valve when its indexed EOA is $<0.90 \mathrm{~cm}^{2} / \mathrm{m}^{2}$ is generally accepted. ${ }^{16}$ The average mean transvalvular gradient in patients with PPM, defined as an indexed EOA $\leq 0.85 \mathrm{~cm}^{2} / \mathrm{m}^{2}$,

TABLE 2. In-hospital outcomes and left ventricular mass index (LVMI) regression

\begin{tabular}{|c|c|c|c|c|c|}
\hline & Group I $(n=224)$ & Group II $(n=52)$ & Group III $(\mathbf{n}=39)$ & Group IV $(n=36)$ & $P$ \\
\hline In-hospital mortality & $3(1.3)$ & $2(3.8)$ & $1(2.8)$ & $0(0.0)$ & .47 \\
\hline Renal failure (dialysis) & $2(1.0)$ & $2(3.8)$ & $1(3.0)$ & $1(3.0)$ & .38 \\
\hline Cerebrovascular accident & $1(0.6)$ & $1(0.8)$ & $0(0.0)$ & $0(0.0)$ & .73 \\
\hline Postoperative bleeding & $5(2.0)$ & $1(0.8)$ & $0(0.0)$ & $9(3.0)$ & .28 \\
\hline LVMI regression $\left(\mathrm{g} / \mathrm{m}^{2}\right)$ & $57.1 \pm 52.0$ & $49.8 \pm 37.7$ & $44.8 \pm 25.1$ & $30.4 \pm 22.8$ & .01 \\
\hline
\end{tabular}

Data are presented as mean \pm standard error or number (\%). LVMI, Left ventricular mass index. 

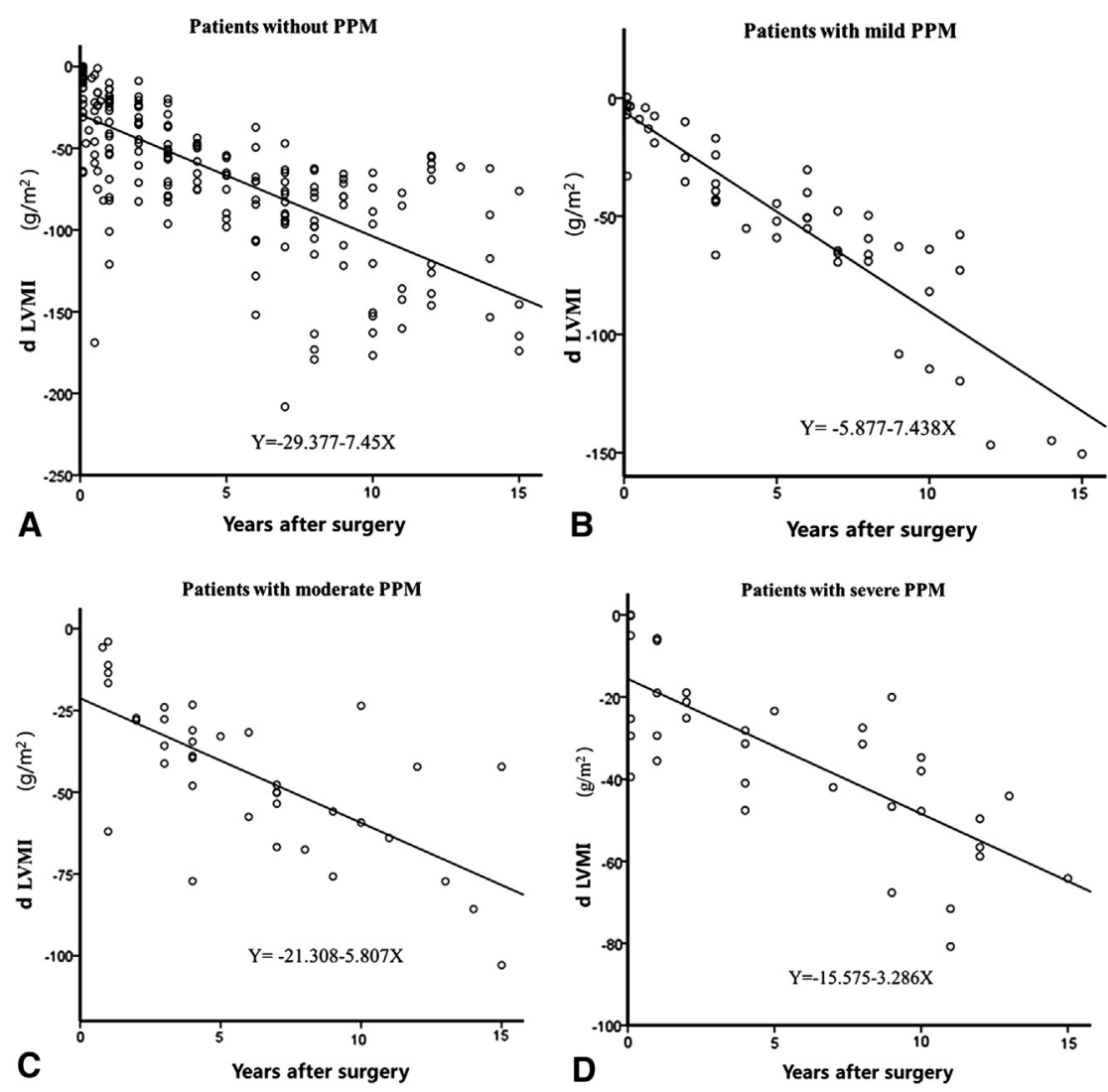

FIGURE 1. The change in left ventricular mass index $(L V M I)$ according to postoperative period. A, Group I, patients without prosthesis-patient mismatch $(P P M) . \mathrm{Y}=-29.377-7.45 \mathrm{X},(95 \%$ confidence interval [CI], -8.507 to $-6.406 ; P<.01)$. B, Group II, patients with mild PPM. Y $=-5.877-7.438 \mathrm{X},(95 \% \mathrm{CI}$, -8.601 to $-6.274 ; P<.01)$. C, Group III, patients with moderate PPM. Y $=-21.308-5.807 \mathrm{X}$, (95\% CI, -7.149 to $-4.465 ; P<.01)$. D, Group IV, patients with severe PPM. Y $=-15.575-3.286 \mathrm{X}(95 \% \mathrm{CI},-4.264$ to $-2.308 ; P<.01)$.

was $22 \pm 8 \mathrm{~mm} \mathrm{Hg}$ compared with only $15 \pm 6 \mathrm{~mm} \mathrm{Hg}$ in patients without PPM and $33 \pm 2 \mathrm{~mm} \mathrm{Hg}$ in patients with an indexed EOA $\leq 0.65 \mathrm{~cm}^{2} / \mathrm{m}^{2} .{ }^{17}$ Mean gradient increase

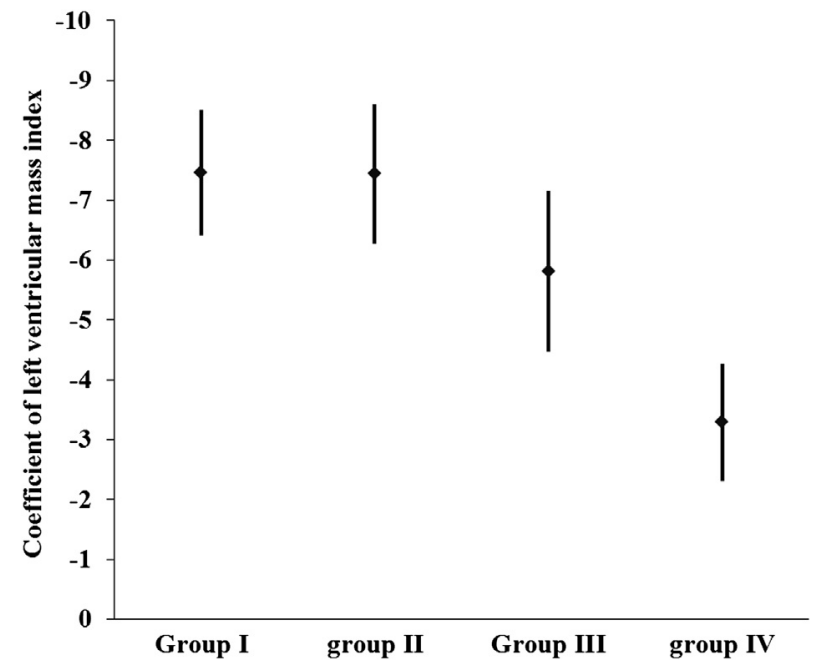

FIGURE 2. The difference of change in left ventricular mass index during the follow-up period. during exercise and average mean gradient in patients with PPM is close to that of patients with moderate AS. ${ }^{18}$ This increased transvalvular gradient will result in increased left ventricle work and could decrease the regression of left ventricular mass.

Could these hemodynamic changes affect patient survival? There are several reports on the relationship between PPM and survival. Not only severe PPM but also moderate PPM may result in adverse affects on long-term survival after AVR. Moderate PPM was associated with increased late mortality in patients with left ventricular dysfunction, and severe PPM had deleterious influences on both early and late mortality. ${ }^{19}$ Considering age, PPM had an adverse influence on survival for young patients. ${ }^{20} \mathrm{PPM}$ has an influence on short- and long-term mortality after AVR. ${ }^{20-22}$ PPM also has a negative influence on exercise capacity due to limitation of the increase in cardiac output during exercise, and has an adverse influence on survival in young patients. ${ }^{23}$ However, other studies have reported that PPM could be common in patients after AVR for aortic stenosis, but severe mismatch was rare and did not affect early or late postoperative survival. ${ }^{24}$ Those studies used 


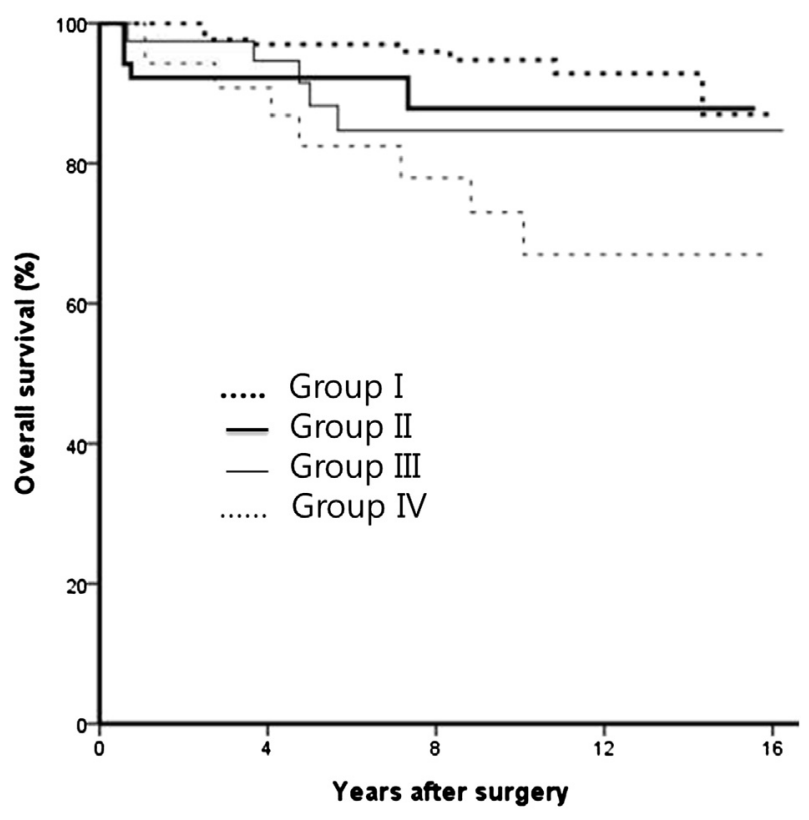

No. of patients.

$\begin{array}{ll}\text { I } & \mathbf{2 2 4} \\ \text { II } & \mathbf{5 6} \\ \text { II } & \mathbf{3 9} \\ \text { IV } & \mathbf{3 6}\end{array}$

143
34
33
22

82
19
16
16

36
7
6
7

FIGURE 3. Overall survival after isolated aortic valve replacement in patients with predominant aortic stenosis.

different parameters such as time interval, in vitro EOA, or geometric orifice area, which are heterogeneous characteristics of patients. These discrepancies show the controversy surrounding the affect of PPM on survival after AVR. It is now widely accepted in the American Society of Echocardiography/American College of Cardiology/American Heart Association/European Association of Echocardiography guidelines that the in vivo indexed EOA is the only valid parameter to identify PPM and predict postoperative gradients and/or adverse clinical outcomes. ${ }^{25}$ We used the in vivo indexed EOA, a homogeneous patient group, and a long-term follow-up period to reduce the bias. Our study shows that PPM did not affect cardiac-related-death-free survival at 3 years, but cardiac-related-death-free survival began to be lower in patients with severe PPM than in those without PPM or with only moderate PPM after 3 years. This suggests that PPM did not affect early survival, but did adversely affect long-term survival. Pibarot and colleagues ${ }^{17}$ reported that cardiac index was similar in patients with and without PPM up to 3 years after AVR, but decreased significantly thereafter only in patients with PPM. Considering this time frame of hemodynamic change, PPM may affect late survival, but not early survival, in agreement with our study results.

Patients with left ventricular dysfunction may be especially vulnerable to the negative effects of PPM. Ruael and colleagues ${ }^{25}$ reported that PPM with an indexed EOA
TABLE 3. Multivariate analysis of potential independent risk factors for overall survival after isolated aortic valve replacement in patients with predominant aortic stenosis during the 12-year follow-up period

\begin{tabular}{|c|c|c|c|}
\hline & $\begin{array}{c}\text { Hazard } \\
\text { ratio }\end{array}$ & $\begin{array}{c}95 \% \text { Confidence } \\
\text { interval }\end{array}$ & $P$ \\
\hline Woman & 0.49 & $0.19-1.26$ & .13 \\
\hline Age (y) & 1.24 & $1.10-1.39$ & .01 \\
\hline $\begin{array}{l}\text { Left ventricle ejection } \\
\text { fraction }<40 \%\end{array}$ & 1.10 & $1.02-1.18$ & .01 \\
\hline Left ventricular mass index & 1.00 & $0.99-1.01$ & .94 \\
\hline Peak pressure gradient & 1.02 & $0.99-1.06$ & .19 \\
\hline Diabetes mellitus & 1.03 & $0.26-4.02$ & .96 \\
\hline Obesity* & 0.87 & $0.21-3.54$ & .85 \\
\hline Hypertension & 1.53 & $0.38-6.08$ & .53 \\
\hline End-stage renal disease & 3.96 & $0.37-41.7$ & .17 \\
\hline Cerebrovascular accident & 3.39 & $0.20-53.2$ & .38 \\
\hline \multicolumn{4}{|l|}{ NYHA Functional Class } \\
\hline II & 0.17 & $0.02-1.42$ & .10 \\
\hline III & 0.67 & $0.09-5.01$ & .70 \\
\hline IV & 18.7 & $1.37-25.5$ & .02 \\
\hline Endocarditis & 3.87 & $0.21-70.3$ & .36 \\
\hline Bioprosthetic valve & 0.42 & $0.13-1.35$ & .15 \\
\hline In vivo $\mathrm{iEOA}$ & 0.22 & $0.01-6.92$ & .32 \\
\hline \multicolumn{4}{|l|}{ PPM } \\
\hline Mild & 2.34 . & $0.57-9.58$ & .23 \\
\hline Moderate & 3.99 & $0.59-27.0$ & .15 \\
\hline Severe & 6.42 & $1.14-35.8$ & .03 \\
\hline
\end{tabular}

NYHA, New York Heart Association; iEOA, in vivo indexed effective orifice area; $P P M$, prosthesis-patient mismatch. *Defined as body mass index $>25$.

of $\leq 0.85$ after AVR primarily affected patients with impaired preoperative left ventricle function and resulted in decreased survival, reduced heart failure-free survival, and incomplete left ventricular mass regression. In our study, because 2 or 3 patients showed preoperative left ventricular dysfunction in Group III or IV, it was difficult to analyze the relationship. But patients with severe PPM had a lower overall survival in preserved left ventricle function, and severe PPM was independent risk factor of cardiac-related death. Based on this clinical outcome, more aggressive surgical correction may be needed to prevent severe PPM when performing AVR.

Thirty-six percent of patients in our study had moderate or severe PPM, which is not a small percentage of patients. It has been reported that $20 \%$ to $70 \%$ of patients undergoing AVR for AS had PPM. ${ }^{15,26}$ In addition, we used the in vivo values instead of the in vitro values derived from premarketing studies, which usually overestimate the in vivo values by $10 \%$ to $15 \% .^{26}$

The proportion of mechanical valve was higher in patients without PPM than in patients with severe PPM, and small prostheses $<19 \mathrm{~mm}$ were implanted predominantly in patients with severe PPM in our study. It is known that if compared with stented bioprosthesis, mechanical valve have a more favorable relationship between its external diameter and the EOA. ${ }^{27}$ Usually, the use of small 


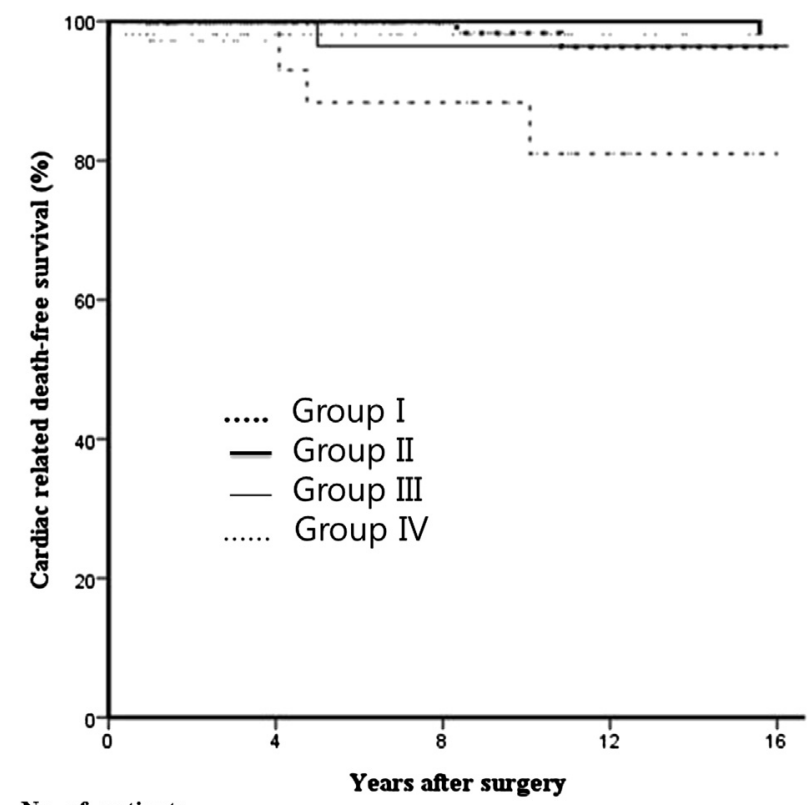

No. of patients.

$\begin{array}{llllll}\text { I } & 224 & 143 & 82 & 36 & 0 \\ \text { II } & 56 & 35 & 20 & 8 & 0 \\ \text { II } & 39 & 39 & 17 & 7 & 1 \\ \text { IV } & 36 & 23 & 17 & 7 & 1\end{array}$

FIGURE 4. Cardiac-related-death-free survival after isolated aortic valve replacement in patients with predominant aortic stenosis.

prostheses $<21 \mathrm{~mm}$ is considered a risk factor for PPM. ${ }^{1}$ However, this finding is applicable to Western patients. In Asian patients who have smaller average body surface areas than Western patients, the use of prostheses $<19 \mathrm{~mm}$ would only be a risk factor for severe PPM.

Considering the change of LVMI with time after AVR, LVMI was decreased in all patients irrespective of presence of PPM. But LVMI of patients with severe PPM was less decreased compared with that of patients without PPM, or with mild or moderate PPM. Other studies showed that patients with left ventricular dysfunction and PPM demonstrated less left ventricular mass regression compared with patients with left ventricular dysfunction and without PPM. ${ }^{26}$ In our study, only patients with severe PPM demonstrated limited left ventricular mass regression during a long-term period. In vivo indexed EOA was not an independent predictor of cardiac-related or overall mortality, and patients with mild or moderate PPM had similar outcomes compared with patients without PPM. Only patients with severe PPM had significantly worse clinical outcomes. These findings suggest that relationship between indexed EOA and risk of mortality may not be linear and that the influence on clinical outcomes becomes significant only when the indexed EOA falls into the severe range.

There are limitations in this study. First, the sample size was too small to assess the interaction between PPM and
TABLE 4. Multivariate analysis of potential independent risk factors for cardiac-related death after isolated aortic valve replacement in patients with predominant aortic stenosis during the 12-year followup period

\begin{tabular}{|c|c|c|}
\hline & $\begin{array}{l}\text { Hazard } \\
\text { ratio }\end{array}$ & $\begin{array}{l}95 \% \text { Confidence } \\
\text { interval }\end{array}$ \\
\hline Woman & 2.79 & $0.22-33.1$ \\
\hline Age (y) & 1.12 & $0.96-1.30$ \\
\hline $\begin{array}{l}\text { Left ventricle ejection } \\
\text { fraction }<40 \%\end{array}$ & 1.21 & $1.12-1.34$ \\
\hline Left ventricular mass index & 1.00 & $0.98-1.10$ \\
\hline Peak pressure gradient & 1.02 & $0.97-1.05$ \\
\hline Diabetes mellitus & 0.52 & $0.02-9.33$ \\
\hline Obesity* & 0.50 & $0.02-8.64$ \\
\hline Hypertension & 4.99 & $0.86-28.9$ \\
\hline End-stage renal disease & 26.3 & $0.75-91.7$ \\
\hline Cerebrovascular accident & 1.30 & $0.06-24.6$ \\
\hline \multicolumn{3}{|l|}{ NYHA Functional Class } \\
\hline II & 10.6 & $0.48-235$ \\
\hline III & 5.97 & $0.18-196$ \\
\hline IV & 18.7 & $2.28-177$ \\
\hline Endocarditis & 3.87 & $0.21-70.3$ \\
\hline Bioprosthetic valve & 0.36 & $0.03-0.89$ \\
\hline In vivo iEOA & 0.97 & $0.03-30.9$ \\
\hline \multicolumn{3}{|l|}{ PPM } \\
\hline Mild & 0.84 . & $0.02-36.0$ \\
\hline Moderate & 1.69 & $0.10-28.5$ \\
\hline Severe & 10.26 & $1.14-92.1$ \\
\hline
\end{tabular}

NYHA, New York Heart Association; $i E O A$, indexed effective orifice area. PPM, prosthesis-patient mismatch. *Defined as body mass index $>25$.

other factors such as age, body mass index, and left ventricular dysfunction. In particular, the number of patients with left ventricular dysfunction in Groups III and IV was insufficient to ensure adequate statistical power for comparing subgroup analysis. Second, various types of prosthesis were implanted, so it was difficult to compare according to type of prosthesis. Third, if the bioprosthesis shows degenerative change, left ventricular mass regression could be decreased. Ten or 12 years had passed since some patients underwent bioprosthesis, and they did not show degenerative change at the time of our study. There are many factors that affect survival and may bias outcomes. To minimize bias, we included only patients who underwent first-time isolated AVR for predominant AS and only cases since 1995 when we began to select various types of prostheses. We studied the clinical relationship between PPM and survival, and further investigation such as pressure gradient, ejection fraction, and left ventricular mass would be required to evaluate the influence of PPM on left ventricle function.

\section{CONCLUSIONS}

Patients with severe PPM showed less decrease in LVMI compared with patients without PPM or with mild or moderate PPM. Severe PPM affected long-term survival but did 
not affect early survival. Further, patients with severe PPM and left ventricle dysfunction could be at increased risk for cardiac-related death during long-term follow-up period.

\section{References}

1. Mohty D, Malouf JF, Girard SE, Schaff HV, Grill DE, Enriquez-Sarano ME, et al. Impact of prosthesis patient mismatch on long-term survival in patients with small St Jude medical mechanical prostheses in aortic position. Circulation. 2006; 113:420-6.

2. Tasca G, Mhagna Z, Perotti S, Centurini PB, Sabatini T, Amaducci A, et al. Impact of prosthesis-patient mismatch on cardiac events and midterm mortality after aortic valve replacement in patients with pure aortic stenosis. Circulation. 2006;113:570-6.

3. Blais C, Dumesnil JG, Baillot R, Simard S, Doyle D, Pibarot P. Impact of valve prosthesis-patient mismatch on short-term mortality after aortic valve replacement. Circulation. 2003;108:983-8.

4. Blackstone EH, Cosgrove DM, Jamieson WR, Birkmeyer NJ, Lemmer JH Jr, Miller DC, et al. Prosthesis size and long-term survival after aortic valve replacement. J Thorac Cardiovasc Surg. 2003;126:783-93.

5. Howell NJ, Keogh BE, Barnet V, Bonser RS, Graham TR, Rooney SJ, et al. Patient-prosthesis mismatch does not affect survival following aortic valve replacement. Eur J Cardiovasc Surg. 2006;30:10-4.

6. Chambers J, Ely JL. Early postoperative echocardiographic hemodynamic performance of the On-X prosthetic heart valve: a multicenter study. J Heart Valve Dis. 1998;7:569-73.

7. Rashtian MY, Stevenson DM, Allen DT, et al. Flow characteristics of bioprosthetic heart valves. Chest. 1990;98:365-75.

8. Desai ND, Christakis GT. Stented mechanical/bioprosthetic aortic valve replacement. In: Cohn LH, Edmunds LH Jr, eds. Cardiac Surgery in the Adult. 2nd ed. Chicago: McGraw-Hill; 2003:825-55.

9. Ihlen H, Molstad P, Simonsen S, Vatne K, Ovrum E, Geiran O, et al. Hemodynamic evaluation of the CarboMedics prosthetic heart valve in the aortic position. Comparison of noninvasive and invasive techniques. Am Heart J. 1992;123:151-9.

10. Chafizadeh ER, Zoghbi WA. Doppler echocardiographic assessment of the St Jude medical prosthetic valve in the aortic position using the continuity equation. Circulation. 1991;83:213-23.

11. Carrel T, Zingg U, Jenni R, Aeschbacher B, Turina MI. Early in vivo experience with the hemodynamic plus St Jude Medical heart valves in patients narrowed aortic annulus. Ann Thorac Surg. 1996;61:1418-22.

12. Pibarot $P$, Dumesnil JG. Prosthetic-patient mismatch: definition, clinical impact, and prevention. Heart. 2006;92:1022-9.

13. Rao V, Jamieson WR, Ivanov J, Amstrong S, David TE. Prosthesis-patient mismatch affects survival after aortic valve replacement. Circulation. 2002; 102:III5-9.

14. Marquez S, Hon RT, Yoganathan AP. Comparative hemodynamic evaluation of bioprosthetic heart valves. J Heart Valve Dis. 2001;10:802-11.

15. Howell NJ, Keogh B, Ray D, Bonser RS, Graham TR, Mascaro J, et al. Patientprosthesis mismatch in patients with aortic stenosis undergoing isolated aortic valve replacement does not affect survival. Ann Thorac Surg. 2010;89:60-4.
16. Bonow RO, Carabello BA, de Leon AC Jr, Edmunds LH Jr, Fedderly BJ, Freed MD, et al. Guidelines for the management of patients with valvular heart disease. Executive summary: a report of the American College of Cardiology/ American Heart Association Task Force on Practice Guidelines (Committee on Management of Patients with Valvular Heart Disease). Circulation. 1998;98: 1949-84.

17. Pibarot P, Dumesnil JG, Lemieux M, Cartier P, Metras J, Durand LG. Impact of prosthesis-patient mismatch on hemodynamic and symptomatic status, morbidity, and mortality after aortic valve replacement with a bioprosthetic heart valve. J Heart Valve Dis. 1998;7:211-8.

18. Burwash IG, Pearlman AS, Kraft CD, Miyake-Hull C, Healy NL, Otto CM. Flow dependence of measures of aortic stenosis severity during exercise. J Am Coll Cardiol. 1994;24:1342-50.

19. Mohty D, Dumesnil JG, Echahidi N, Mathieu P, Dagenais F, Voisine P, et al. Impact of prosthesis-patient mismatch on long-term survival after aortic valve replacement. J Am Coll Cardiol. 2009;53:39-47.

20. Moon MR, Pasque MK, Munfakh NA, et al. Prosthesis-patient mismatch after aortic valve replacement: impact of age and body size on late survival. Ann Thorac Surg. 2006;81:481-8.

21. Walther T, Rastan A, Falk V, Lehman S, Garbade J, Funkat AK, et al. Patients prosthesis mismatch affects short- and long-term outcomes after aortic valve replacement. Eur J Cardiothorac Surg. 2006;30:15-9.

22. Kohasaka S, Mohan S, Virani S, Lee VV, Contreras A, Reul GJ, et al. Prosthesispatient mismatch affects long-term survival after mechanical valve replacement. J Thorac Cardiovasc Surg. 2008;135:1076-80.

23. Bleiziffer S, Eichinger WB, Hettich I, Ruzicka D, Wottke M, Bauernschmitt R, et al. Impact of patient-prosthesis mismatch on exercise capacity in patients after bioprosthetic aortic valve replacement. Heart. 2008;94:637-41.

24. Zoghbi WA, Chambers JB, Dumesnil JG, Foster E, Gottdiener JS, Grayburn PA, et al. Recommendations for evaluation of prosthetic valves with echocardiography and Doppler ultrasound: a report from the American Society of Echocardiography's Guidelines and Standards Committee and the Task Force on Prosthetic Valves, developed in conjunction with the American College of Cardiology Cardiovascular Imaging Committee, Cardiac Imaging Committee of the American Heart Association, the European Association of Echocardiography, a registered branch of the European Society of Cardiology, the Japanese Society of Echocardiography and the Canadian Society of Echocardiography, endorsed by the American College of Cardiology Foundation, American Heart Association, European Association of Echocardiography, a registered branch of the European Society of Cardiology, the Japanese Society of Echocardiography, and Canadian Society of Echocardiography. J Am Soc Echocardiogr. 2009;22: 975-1014.

25. Ruel M, Al-Faleh H, Kulik A, Chan KL. Prosthesis-patient mismatch after aortic valve replacement predominantly affects patients with preexisting left ventricular dysfunction: effect on survival, freedom from heart failure, and left ventricular mass regression. J Thorac Cardiovasc Surg. 2006;131:1036-44.

26. Pibarot P, Dumesnil JG. Hemodynamic and clinical impact of prosthesis-patient mismatch in the aortic valve position and its prevention. J Am Coll Cardiol. 2000; 36:1131-41.

27. Munneretto C, Bisleri G, Negri A, Manfredi J. The concept of patient-prosthesis mismatch. J Heart Valve Dis. 2004;13(Suppl):S59-62. 